\title{
Oil palm empty fruit bunch as alternative substrate for acetone-butanol-ethanol production by Clostridium butyricum EB6
}

\begin{abstract}
Acetone-butanol-ethanol (ABE) production from renewable resources has been widely reported. In this study, Clostridium butyricum EB6 was employed for ABE fermentation using fermentable sugar derived from treated oil palm empty fruit bunch (OPEFB). A higher amount of $\mathrm{ABE}(2.61 \mathrm{~g} / \mathrm{l})$ was produced in a fermentation using treated OPEFB as the substrate when compared to a glucose based medium that produced $0.24 \mathrm{~g} / \mathrm{l}$ at $\mathrm{pH} 5.5$. ABE production was increased to $3.47 \mathrm{~g} / \mathrm{l}$ with a yield of $0.24 \mathrm{~g} / \mathrm{g}$ at $\mathrm{pH} 6.0$. The fermentation using limited nitrogen concentration of $3 \mathrm{~g} / \mathrm{l}$ improved the ABE yield by $64 \%$. The study showed that OPEFB has the potential to be applied for renewable ABE production by $\mathrm{C}$. butyricum EB6.
\end{abstract}

Keyword: Clostridium butyricum; Acetone butanol ethanol (ABE); Oil palm empty fruit bunch (OPEFB); Anaerobic fermentation; Biomass 